\title{
Interaction between Caffeine and Adenosine on the Membrane Current and Tension Component in the Bullfrog Atrial Muscle
}

\author{
Masayoshi Goto, Atsuko Yatani, and Tsuguhisa Ehara \\ Department of Physiology, Faculty of Medicine, \\ Kyushu University, Fukuoka, 812 Japan
}

\begin{abstract}
Antagonistic action of caffeine and adenosine were studied at the membrane current and tension component levels in myocardium of the bullfrog atrium, mainly under voltage clamp using the double sucrose-gap method.

Caffeine (1-5 mM) produced marked augmentation of the phasic and tonic tensions as well as slow inward current $\left(I_{\mathrm{s}}\right)$. At higher concentrations it elicited an increase of the delayed outward current $\left(I_{\mathrm{x}}\right)$. The augmentation of $I_{\mathrm{s}}$ was principally due to increase of the limiting conductance $\left(\bar{g}_{\mathrm{s}}\right)$, while the activation and inactivation variables $\left(d_{\infty}, f_{\infty}\right)$ were not changed significantly. The dose-tension response curve for caffeine, which appeared sigmoidal, was notably lowered in the presence of adenosine (1-3 mM), indicating a competitive type of inhibition. Adenosine, in the presence of caffeine, exerted a narcotic-like action by inhibiting all of the membrane currents $\left(I_{\mathrm{Naf}}, I_{\mathrm{s}}, I_{\mathrm{x}}\right.$ and background inward current, $\left.I_{\mathrm{b}}\right)$ and tension components $\left(I_{\mathrm{Ca}}\right.$-dependent and independent tensions). The inhibition of $I_{\mathrm{s}}$ was due to a decrease of $\bar{g}_{\mathrm{s}}$ and no appreciable change was observed in $d_{\infty}$ and $f_{\infty}$. These results suggest that adenosine has a strong stabilizing action on the myocardium, especially when the heart muscle activity is accelerated by increased cyclic AMP.
\end{abstract}

Much work has been done on the effects of adenosine and its phosphorylated derivatives in cardiac muscle since the original report by DRURY and SzENTGyöRGYI (1929). It has been established that adenosine, a powerful coronary vasodilator, exerts a negative inotropic effect on myocardium by shortening the action potential (JoHNSON and MCKINNON, 1956; HollaNDER and WeBb, 1957; DE GubarefF and Sleator, 1965; Meinertz et al., 1973) which was determined to be caused by depression of Ca inward current (SCHRADER et al., 1975, 1977; Goto et al., 1978).

DE GUBAREFF and SLEATOR (1965) demonstrated that caffeine antagonizes the depressant effect of adenosine on contraction and action potentials in guinea-pig

Received for publication December 26, 1978

後藤昌義, 八谷アッ子, 頴原嗣尚 
and human atrial muscle, and suggested that the antagonism between these two drugs may reflect their opposite effects on Ca exchangeability. GROSSMAN and FURCHGOTT (1964) studied the action of several drugs on Ca flux and found that the negative inotropic effect of adenosine in the guinea-pig atria was associated with a significant reduction in the exchangeability of tissue $\mathrm{Ca}$. The effect of adenosine is in contrast with that of caffeine, which has been shown to increase Ca exchangeability in amphibian and mammalian heart muscles (NAYLER, 1963; GUTHRIE and NAYLER, 1967).

No further analysis of the antagonistic effects between adenosine and caffeine, however, has been done on the membrane current and tension component levels in myocardium. Therefore, the present experiments were undertaken to clarify the mode of interaction of caffeine and adenosine in the bullfrog atrium, mainly under voltage clamp. The observations substantiated the interaction of two substances on the membrane current and tension components.

\section{METHODS}

Thin muscle bundles of $0.3-0.5 \mathrm{~mm}$ diameter and 5-6 $\mathrm{mm}$ length were dissected from the left atrium of the bullfrog. A preparation was mounted in a chamber with five compartments separated by four diaphragms with holes in their centers through which the muscle was passed. By means of a conventional double sucrose-gap method, the membrane potential, current and tension of the muscle were measured simultaneously under voltage-clamped and unclamped conditions. A detailed description of the chamber and experimental apparatus is given in preceding papers (YATANI et al., 1978; TSUDA, 1979). Briefly, the central test compartment was $0.3-0.4 \mathrm{~mm}$ in width, and the left and right intermediate compartments were $1.0 \mathrm{~mm}$ and perfused with isotonic sucrose solution $(250.5 \mathrm{~mm})$. The terminal compartments were large pools filled with isotonic $\mathrm{KCl}$ solution (127 mM). Two diaphragms between the central and left terminal compartments were each composed of two close fitting and one slotted film plate and were utilized for fixing the preparation. The two on the right side were rubber membranes. The muscle was pulled through the tightly fitting holes and connected to a strain gauge (Nihon Kohden SB-1T) for tension measurement in the terminal compartment. With this apparatus, gap action potentials exceeding $100 \mathrm{mV}$ were commonly obtained for 4-5 hr showing a short circuit factor of more than 0.8 .

All experiments were performed at a constant temperature of $17 \pm 0.5^{\circ} \mathrm{C}$ except where noted in the text. The normal Ringer solution which was perfused through the test compartment had the following composition in $\mathrm{mM}, \mathrm{NaCl} 110.0, \mathrm{KCl} 2.5$, $\mathrm{CaCl}_{2}$ 1.8, $\mathrm{Na}_{2} \mathrm{HPO}_{4} 2.15, \mathrm{NaH}_{2} \mathrm{PO}_{4}$ 0.85, glucose 10.0 and a $\mathrm{pH}$ of 7.4. In Ringer solution containing Mn, $3 \mathrm{~mm}$ Mn was added, and Tris buffer, Tris(hydroxymethyl) aminomethane- $\mathrm{HCl}(10 \mathrm{~mm})$, was used. In the various test solutions, drugs such as caffeine and adenosine were simply added without regulating osmotic pressure. 
The possible effects of increased osmolarity were examined by increasing glucose concentration up to $25.0 \mathrm{~mm}$ and no appreciable change was observed.

The muscle was driven at a frequency of $0.1 \mathrm{~Hz}$ with square wave pulse $(6 \mathrm{msec}$, about twice threshold voltage). Whenever voltage clamp was used, the membrane potential was usually held at the gap resting potential $(-70--75 \mathrm{mV})$ and depolarizing or hyperpolarizing pulses were applied at the same frequency. When the inactivation curves of slow inward current were determined with long pulses (see RESUlTs 4), the holding potential was increased to $-100 \mathrm{mV}$ and the pulse intervals were lengthened to $30 \mathrm{sec}$.

A cumulative dose-response curve for caffeine and a dose-dependent inhibition curve for adenosine (see RESULTS 1) were determined by the methods previously described (YATANi et al., 1978). For these tests, the right side sucrose compartment was omitted by removing the rubber membranes, and the large terminal compartment was utilized as the test chamber. After an equilibration time of more than $60 \mathrm{~min}$, the normal Ringer solution in the chamber was replaced with a test solution. In the experiments in which effects of prior presence of caffeine or adenosine were examined, each drug was applied more than $30 \mathrm{~min}$ before the determination of the dose-response curves. In these dose-tension response experiments, Ca concentration in both the control and drug containing Ringer solutions was reduced to $0.5 \mathrm{~mm}$ in order to see the inotropic effect more clearly without saturation of tension.

\section{RESULTS}

1. General effects of caffeine and adenosine, and their dose-dependent interactions

Previous experiments in our laboratory have shown that in the bullfrog atrium caffeine (3-20 mM) causes a sustained potentiation of contraction without eliciting contracture and a prolongation of action potential accompanied by retardation of tension relaxation (Кімото et al., 1974); and that adenosine (1-5 mM) produces an initial augmentation and a late sustained depression of contraction accompanied by a prolongation and a late shortening of action potential (Gото et al., 1978). Most of these results were reconfirmed in the present experiments. However, when adenosine (1-3 mM) was added in the presence of caffeine (1-5 mM), the action potential was always shortened and contraction was depressed. Figure $1 \mathrm{~A}, \mathrm{~B}$ and $\mathrm{C}$ shows examples of the effects of caffeine $(3,5 \mathrm{~mm})$ and further addition of adenosine (1 mM). As seen, caffeine markedly increased the twitch tension and prolonged the action potential as well as the contraction. When adenosine was applied after 10 min treatment with, and still in the presence of caffeine, the duration of action potential shortened and the contraction diminished. These effects of caffeine plus adenosine on the frog atrium resembled those observed on guineapig atrium (DE GUBAREFF and SLEATER, 1965), but were far less prominent.

To estimate the general degree of interaction between adenosine and caffeine 

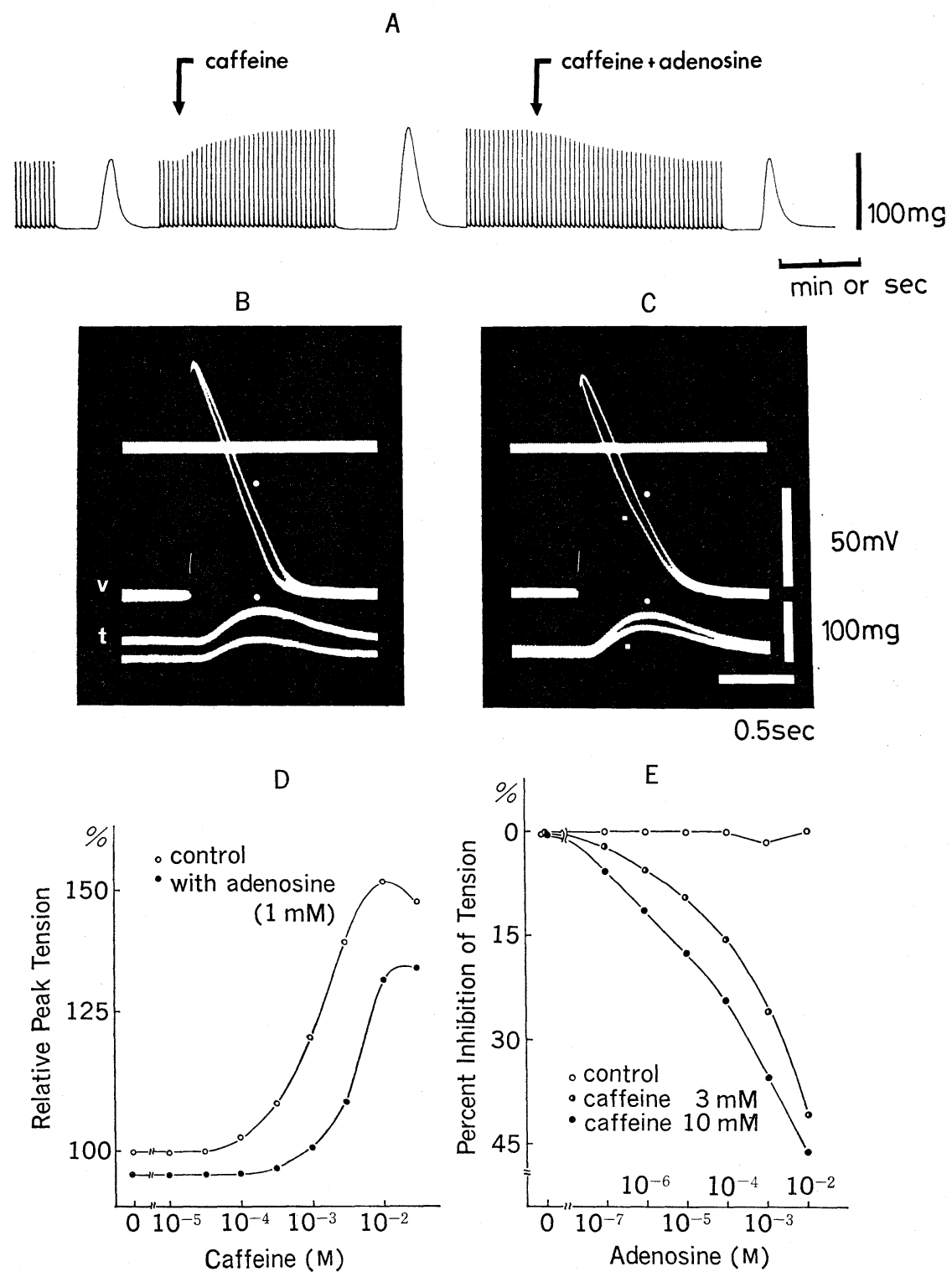

Fig. 1. General effects of caffeine and adenosine on the bullfrog atrium. A) Effects of caffeine $(3 \mathrm{~mm})$ and further addition of adenosine $(1 \mathrm{~mm})$ on twitch contraction. $B, C)$ Effects on membrane potential $(v)$ and contractile tension $(t)$. B: Records before and $3 \mathrm{~min}$ (white dot) after caffeine $(5 \mathrm{~mm})$. C: Records $5 \mathrm{~min}$ (white dot) after caffeine $(5 \mathrm{~mm})$ and $7 \mathrm{~min}$ (white square) after further addition of adenosine (1 mM). A shift of basal tension in $\mathrm{B}$ was not common. D) Dose-tension response curves for caffeine in the absence $(O)$ and presence $(\bullet)$ of adenosine $(1 \mathrm{mM})$. E) Dose-dependent inhibition of twitch tension by adenosine in absence $(O)$ and presence of caffeine $(\bullet, 3 ; 0,10 \mathrm{mM})$. $\mathrm{D}$ and $\mathrm{E}$ show a mean of four series of experiments. In $\mathrm{D}$, response in normal Ringer solution taken as $100 \%$. E is percent inhibition from control tension before adenosine. 
in the bullfrog atrium, dose-tension response curves for each drug in the presence and absence of the other drug were examined. Figure $1 \mathrm{D}$ shows the dose-response relationship for caffeine and the effects of adenosine on the relationship. Caffeine produced a dose-dependent augmentation of the twitch contraction as expected. The threshold concentration was $5 \times 10^{-5}-10^{-4} \mathrm{M}$, and the maximal response was obtained at about $10^{-2} \mathrm{M}$. In the presence of $3 \mathrm{~mm}$ adenosine, the effects of caffeine were substantially decreased. The threshold concentration and the maximally effective dose were both raised, and the half-activation value was shifted from $2 \times 10^{-3} \mathrm{M}$ in the control without adenosine to $7 \times 10^{-3} \mathrm{M}$ with adenosine. These results may suggest a competitive rather than a non-competitive type of inhibition by adenosine.

Figure $1 \mathrm{E}$ shows dose-dependent adenosine inhibition of twitch contractions which had been initially augmented by caffeine. As can be seen, adenosine alone at less than $10^{-3} \mathrm{M}$ produced no appreciable effect on the twitch tension. In the presence of caffeine $(3 \mathrm{mM})$, however, the contraction was markedly depressed by adenosine in a dose-dependent manner, and the inhibition became more pronounced at a higher concentration of caffeine $(10 \mathrm{~mm})$. It should be noted that the absolute value of the $0 \%$ point is different for the three conditions (see Fig. $1 \mathrm{D}$, control). The threshold concentration of inhibition by adenosine was lowered from $10^{-3} \mathrm{M}$ in the absence to less than $10^{-7} \mathrm{M}$ in the presence of caffeine. Thus, the prior presence of caffeine enhanced the inhibitory action of adenosine.

Similar experiments were also conducted on the dose-tension relationship for theophylline (not shown). In this case, the inhibitory effects of adenosine were less apparent than in the case of caffeine. The half-maximal concentration of theophylline was shifted from $7 \times 10^{-4} \mathrm{M}$ in the control to $10^{-3} \mathrm{M}$ in the presence of adenosine (1 mM).

\section{The effects of caffeine and adenosine on the slow inward current under voltage} clamp

KIмото et al. (1974) first studied the effects of caffeine on membrane currents in the bullfrog atrium under voltage clamp conditions, and determined that caffeine produced augmentation of the slow inward current together with enhancement of the delayed outward current. No further study, however, has been done on the kinetics and current-voltage relationships. In the present experiments, analysis of the detailed effects and the interactions between caffeine and adenosine was performed.

Figure 2 A shows the effects of caffeine ( $5 \mathrm{~mm}$ ) and subsequent addition of adenosine $(1 \mathrm{mM})$ which were examined with short step pulses in the constant presence of tetrodotoxin (TTX, $\left.1.5 \times 10^{-6} \mathrm{M}\right)$. The slow inward current $\left(I_{\mathrm{s}}\right)$ was markedly enhanced by caffeine and depressed by adenosine, but the time-course of activation and inactivation was not affected. Figure 2 B shows results obtained with long step pulses of different amplitudes, but in this case adenosine ( $3 \mathrm{mM})$ was replaced 



Fig. 2. Effects of caffeine and adenosine on the membrane current (i) under voltage clamp (v) in constant presence of TTX $\left(1.5 \times 10^{-6} \mathrm{M}\right)$. A) Effects on response to short $(0.1 \mathrm{sec})$ step pulse of $60 \mathrm{mV}$ depolarization. a, control; b, 4 min after caffeine (5 mM); c, $5 \mathrm{~min}$; and d, $15 \mathrm{~min}$ after further addition of adenosine (1 mM). B) Responses to long step pulses of $1.6 \mathrm{sec}$ duration and different amplitudes of depolarization. a, control; b, 5-8 min after caffeine (5 mM); and c, 8-12 min after replacement of caffeine with adenosine $(3 \mathrm{~mm})$. Note marked augmentation of $I_{\mathrm{S}}$ by caffeine and depression of $I_{\mathrm{S}}$ and $I_{\mathrm{x}}$ by adenosine. Holding potential was $-73 \mathrm{mV}$ throughout.

after caffeine (5 mM). Again, the slow inward current was markedly enhanced by caffeine, but depressed by adenosine to less than the control value, while the delayed outward current $\left(I_{\mathrm{x}}\right)$ was inhibited slightly by caffeine, and strongly by adenosine. Under the action of these drugs, however, neither the instantaneous outward current nor the reversal potential of slow inward current were changed appreciably.

Figure 3 illustrates the current voltage relationships. Caffeine ( $5 \mathrm{~mm})$ produced a marked enhancement of the slow inward current without altering the voltage of the peak current. The delayed outward current appeared rather depressed, initially (5-8 min after application), but longer exposure of more than $20 \mathrm{~min}$ or higher concentration of caffeine (10 and $20 \mathrm{~mm}$ ) caused a gradual augmentation of the outward current and a rise in threshold voltage of the slow inward current. The background currents $\left(I_{\mathrm{b}}\right)$ for hyperpolarizing and depolarizing pulses (mainly $I_{\mathrm{k} 1}$ ) were virtually unchanged, although they did tend to increase in the higher concentrations of the drug.

When adenosine was added in the presence of caffeine, or when caffeine was 

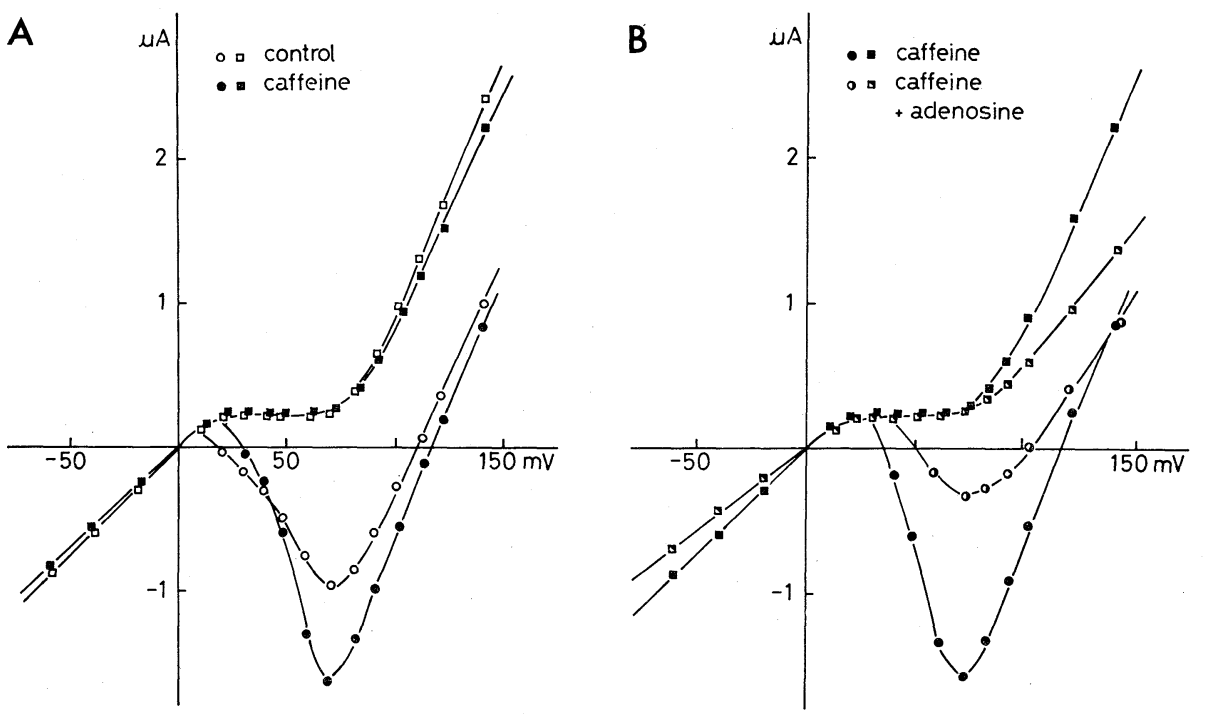

Fig. 3. Voltage-current relationships and effects of caffeine and adenosine in constant presence of TTX. Depolarizing and hyperpolarizing step pulses of $2.0 \mathrm{sec}$ duration were applied from holding potential of $-75 \mathrm{mV}$. A) Controls $(O, \square)$ and relationships 5-8 min after application of caffeine (5 mM, $\bullet, \mathbf{\square})$. B) Relationships 8-12 min after caffeine $(5 \mathrm{~mm}, \bullet, \mathbf{\square})$ in different series, and $8-13 \mathrm{~min}$ after replacing with adenosine $(3 \mathrm{~mm}$, D, I). In both figures, circles denote peak values of $I_{\mathrm{s}}$, and squares, terminal current levels for $2.0 \mathrm{sec}$ pulse. Control shows mean of each two series before caffeine and 15 and 20 min after washout. Data in presence of caffeine or adenosine show mean of two series. Times denote start of each examination. Situations are same in following figures.

simply replaced with adenosine, a marked depression of the augmented $I_{\mathrm{s}}$ occurred together with a conspicuous inhibition of the background and delayed outward currents (Fig. 3 B). These effects of adenosine in the presence of caffeine were considerably different from effects in the presence of adrenaline (Goto et al., 1978) in which the $I_{\mathrm{s}}$ was selectively suppressed.

3. Effects of caffeine and adenosine on the membrane currents in the presence of Mn (Fig. 4)

In order to observe the action of the drugs on the inward or outward background currents and on the delayed outward current in better detail, the effects were examined in Ringer solution containing Mn. This eliminated the slow inward current and any remaining current appeared to be rather isolated. An unexpected observation in these experiments was that caffeine $(5 \mathrm{mM})$ often produced augmentation of the fast inward sodium current $\left(I_{\mathrm{Naf}}\right)$. The background currents in response to hyperpolarizing or depolarizing pulses and the delayed outward current were virtually unchanged or tended to be depressed. Since depres- 

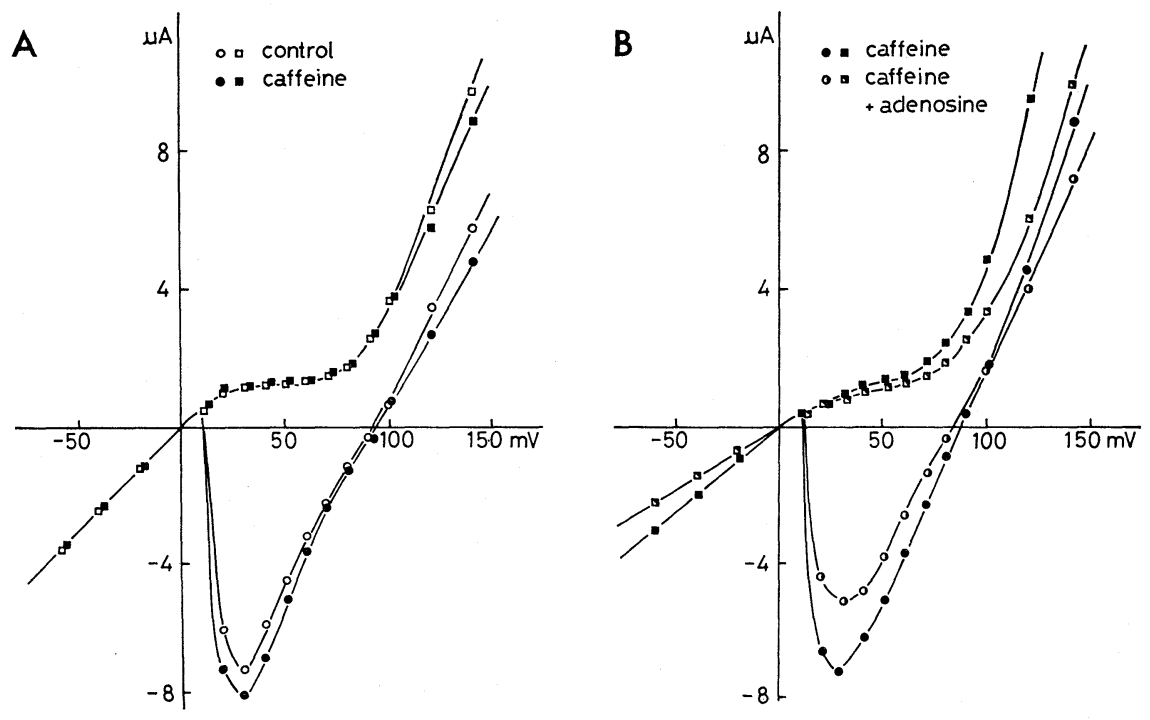

Fig. 4. Voltage-current relationships in presence of $\mathrm{Mn}(3 \mathrm{~mm})$, and effects of caffeine and adenosine. A) Controls $(\bigcirc, \square)$ and relationships 6-10 min after application of caffeine (5 mM, - , ). B) Relationships 24-28 min after caffeine $(5 \mathrm{~mm}, \boldsymbol{\bullet}, \boldsymbol{\square})$ in the same series, and 12-16 min after further addition of adenosine ( $3 \mathrm{~mm}, \boldsymbol{\nabla}, \nabla)$. Circles denote peak value of $I_{\mathrm{Naf}}$, and squares, terminal current levels. $I_{\mathrm{Naf}}$ was enhanced by caffeine and depressed by adenosine. Note also increase of background and delayed outward currents in later phase $(B, \mathbf{E})$ in comparison with initial phase $(A, \mathbf{E})$ after caffeine. Holding potential: $-70 \mathrm{mV}$ throughout. Step pulses: $2.0 \mathrm{sec}$ duration.

sion of these currents may improve voltage control during clamp, the observed slight enhancement of fast inward current may have no significance.

However, when adenosine $(3 \mathrm{~mm})$ was added in the presence of caffeine, considerable inhibition of the fast inward current was produced together with a further depression of the background and delayed outward currents (Fig. 4 B). These observations, when considered in connection with the results on the sole action of adenosine (Gото et al., 1978), may support the conclusion that the fast inward current is actually depressed by adenosine.

It must be also noted that the inhibitory effects of adenosine on the terminal current levels $\left(I_{\mathrm{b}}\right.$ and $\left.I_{\mathrm{x}}\right)$ in the Mn Ringer solution appeared qualitatively to parallel those in the Ca-free, $10^{-5} \mathrm{M}$ EDTA Ringer solution (not shown). In this solution, as well, the background inward current on hyperpolarization and outward current on depolarization and the delayed outward current were depressed by adenosine. Since, in the former solution, net concentration of divalent cations was increased with $\mathrm{Ca}$ ions in the Ringer plus $\mathrm{Mn}$ ions, while in the latter $\mathrm{Ca}$ concentration was reduced to less than $10^{-7} \mathrm{M}$ with EDTA, the cause of inhibition of these currents by adenosine may not relate to the concentration change of ex- 
ternal divalent cations, but rather correlate with a depression of Ca-influx across the membrane.

4. Kinetic analysis of the effect of caffeine and adenosine on the slow inward current Figure 5 illustrates a kinetic analysis of the slow inward current $\left(I_{\mathrm{s}}\right)$, i.e., determination of the activation and inactivation variables ( $d$ and $f$ ) and the limiting conductance $\left(\bar{g}_{\mathrm{s}}\right)$ by means of the step clamp method which was originally proposed by Reuter (1974) and Trautwein et al. (1975). The figure shows the results for the variable $d(\mathrm{~A})$, and the variable $f(\mathrm{~B})$, plus the program of step pulse used for determination of each variable in the respective insets. For $d$, the tail current immediately after short $(50 \mathrm{msec})$ depolarizing pulses having different amplitudes was measured after extrapolating the semilogarithmic plots of the tail to the end of pulse, and this value of current was plotted against the depolarization voltage, as usual. For $f$, the peak inwardly directed current during the third, test pulse was measured from the terminal outward current level, and this value was plotted against the voltage of the second, conditioning step pulse. However, possible errors due to the delayed outward current must be considered (see below).
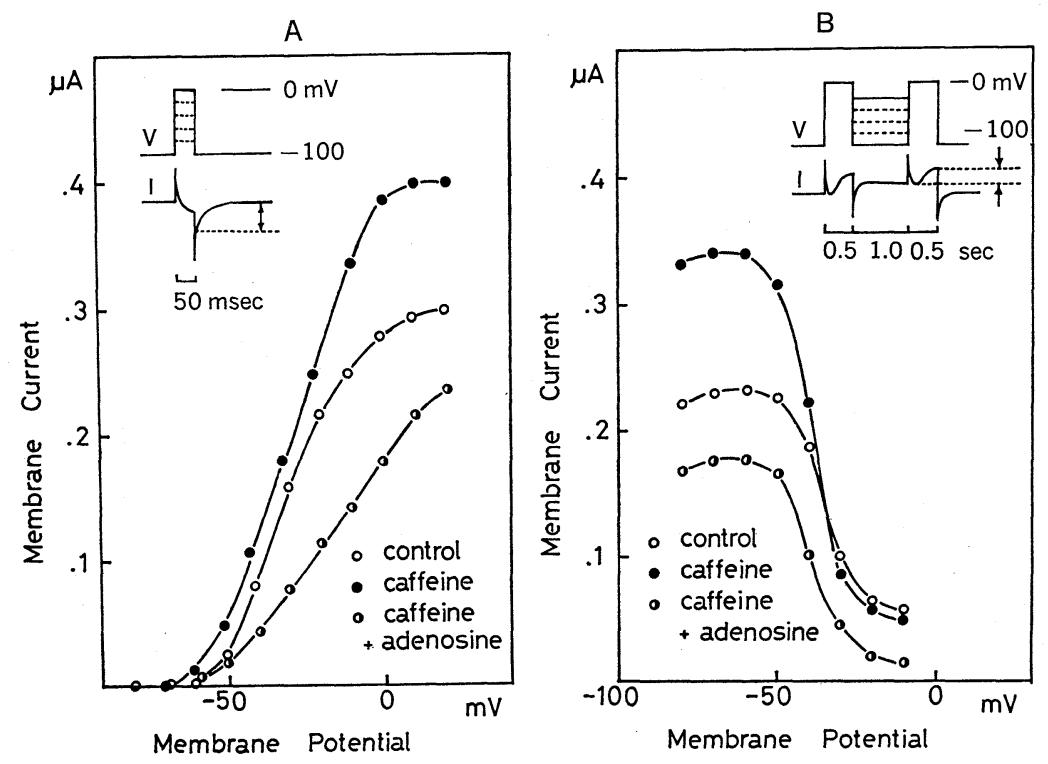

Fig. 5. Steady state activation and inactivation of slow inward current, and effects of caffeine and adenosine. A) Activation curves before (O), 6-13 $\mathrm{min}$ after caffeine ( $5 \mathrm{~mm}$, •) and 15-20 min after further addition of adenosine (3 mM, $)$. B) Inactivation curves before $(0), 7-21 \mathrm{~min}$ after caffeine $(5 \mathrm{mM}, \bullet)$, and 10-20 min after further addition adenosine $(3 \mathrm{~mm}, \mathbf{1})$. All plots are mean of three series of experiments. Each figure inset shows details of step pulses and measurement of the current. Amplitude of current was plotted against voltage of conditioning step pulse. Further explanation in text.

Vol. 29, No. 4, 1979 
As can be seen in these figures, in which a mean of four series of experiments was plotted, both the activation and inactivation curves were markedly augmented by caffeine $(5 \mathrm{~mm})$, and depressed by subsequent addition of adenosine $(3 \mathrm{~mm})$. However, no appreciable shift of the curves along the voltage axis was observed. The downward shift of the inactivation curve after adenosine (Fig. 5 B) was simply due to a marked reduction of the delayed outward current (see Fig. 3 B).

Figure 6 shows the actual records in one series of the experiments in which the figure (A) is control records and (B), those after addition of caffeine (5 mM). TTX was present throughout. The inwardly directed current in response to the third, test pulse was markedly enhanced by caffeine (a). The current, however, was gradually depressed by increasing the second, conditioning depolarization (b-d) and finally disappeared (e) as expected. The grade and mode of depression, however, appeared to be quite parallel to those of controls. Note also that the
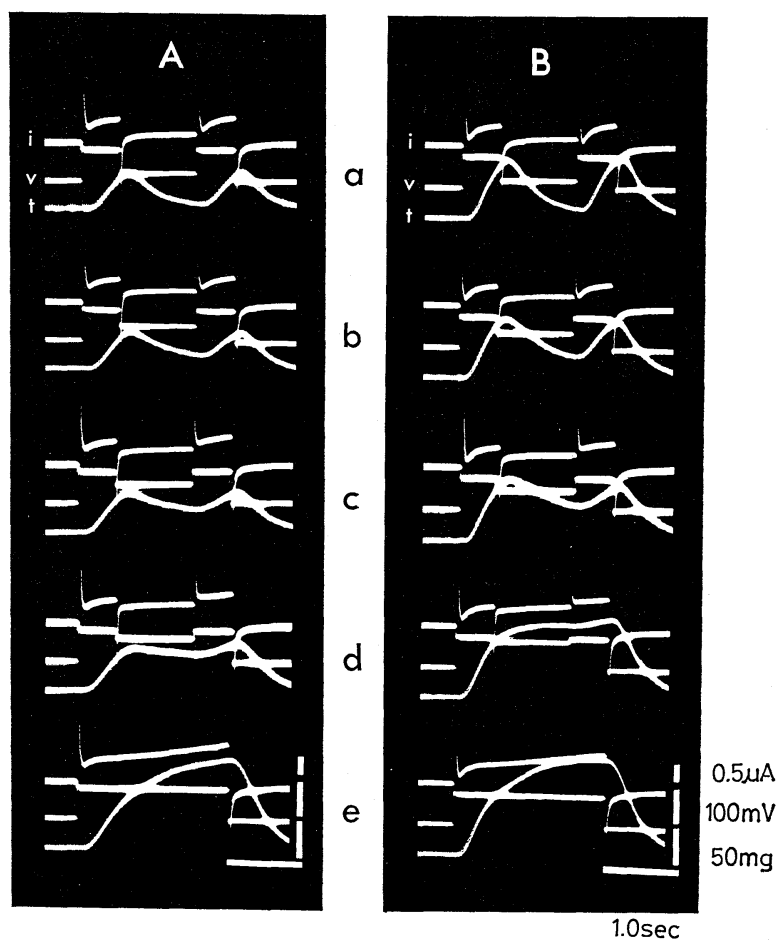

Fig. 6. Example records of the membrane potential (v), current (i) and tension ( $t$ ) used for determination of the inactivation variable. TTX was present throughout and the program of step pulses was the same as in Fig. 5B (inset). A) Control records. B) Records 7-13 min after caffeine ( $5 \mathrm{~mm})$. Caffeine augmented slow inwardly directed current and tension development in response to both first and third step pulses. Note also gradual depression of current and tension response to third test pulse as second conditioning depolarization pulse increased in both $\mathrm{A}$ and $\mathrm{B}$. 

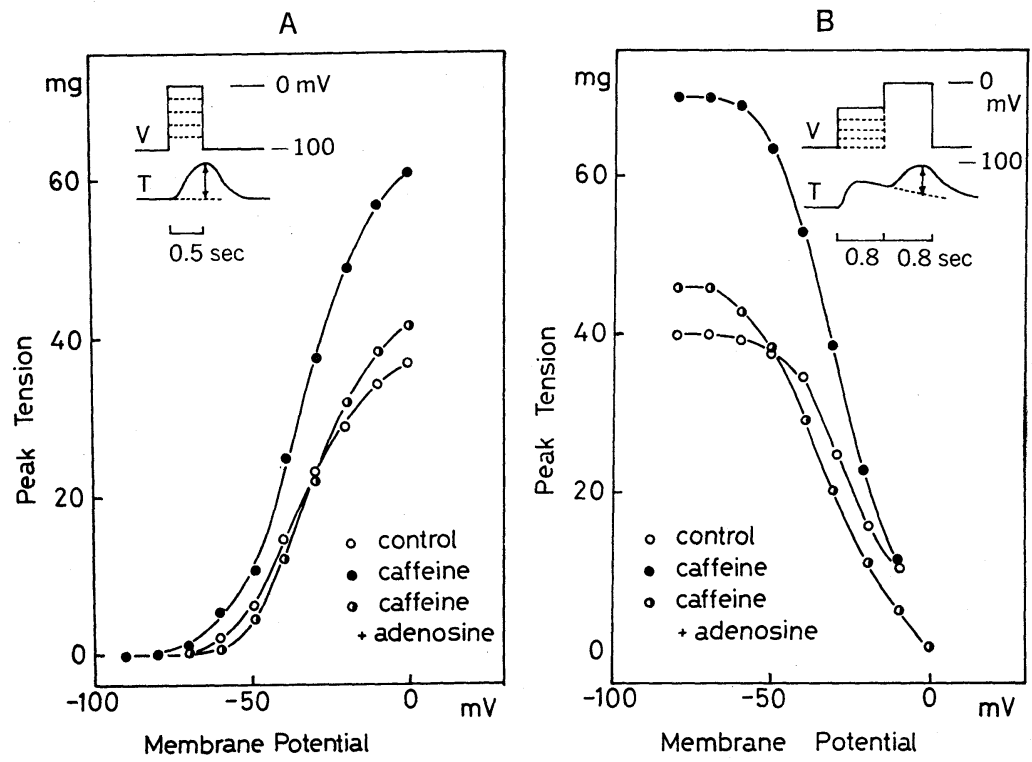

Fig. 7. Steady state activation and inactivation of slow inward current determined by tension measurement method, and effects of caffeine and adenosine. Programs of step depolarization and measurement of tension were shown in inset. TTX was present throughout. A) Activation curves before (O), 4-15 min after caffeine (5 $\mathrm{mm}, \bullet)$, and 5-20 min after further addition of adenosine ( $3 \mathrm{~mm}, \mathbf{0})$. B) Inactivation curves before $(0)$, 4-13 min after caffeine ( $\bullet$ ), and 5-20 min after further addition of adenosine ( $\mathbf{(})$. Means of three series were used for plots.

phasic tension responses to the third test pulses showed changes which were very similar to those of the slow inward current.

Figure 7 shows similar results for the activation and inactivation variables, and $\bar{g}_{\mathrm{Ca}}$ which were determined by the voltage clamp and tension measurement method, proposed by TraUtWEIN et al. (1975) and HoraCKOVA and VASSORT (1976). The programs of depolarizing pulse and measurement of tension are illustrated in the insets. As seen, the results are quite comparable to those of Fig. 5 which were obtained with the current measurement method. Again, caffeine (5 mM) augmented and further addition of adenosine ( $3 \mathrm{~mm}$ ) inhibited both the augmented activation and inactivation curves, although the inactivation curves appear to be less steep in this figure than those obtained by the current method (Fig. 5 B). If the activation and inactivation curves are superposed on the same voltage axis, the coupled curves would cross to each other at about $-35--40 \mathrm{mV}$, and when normalized, they overlap in most parts and show no appreciable shift along the voltage axis. Thus, it can be concluded that caffeine increases and adenosine decreases the $\bar{g}_{\mathrm{s}}$ without appreciably affecting the parameters of steady state activation and inactivation $\left(d_{\infty}, f_{\infty}\right)$. 

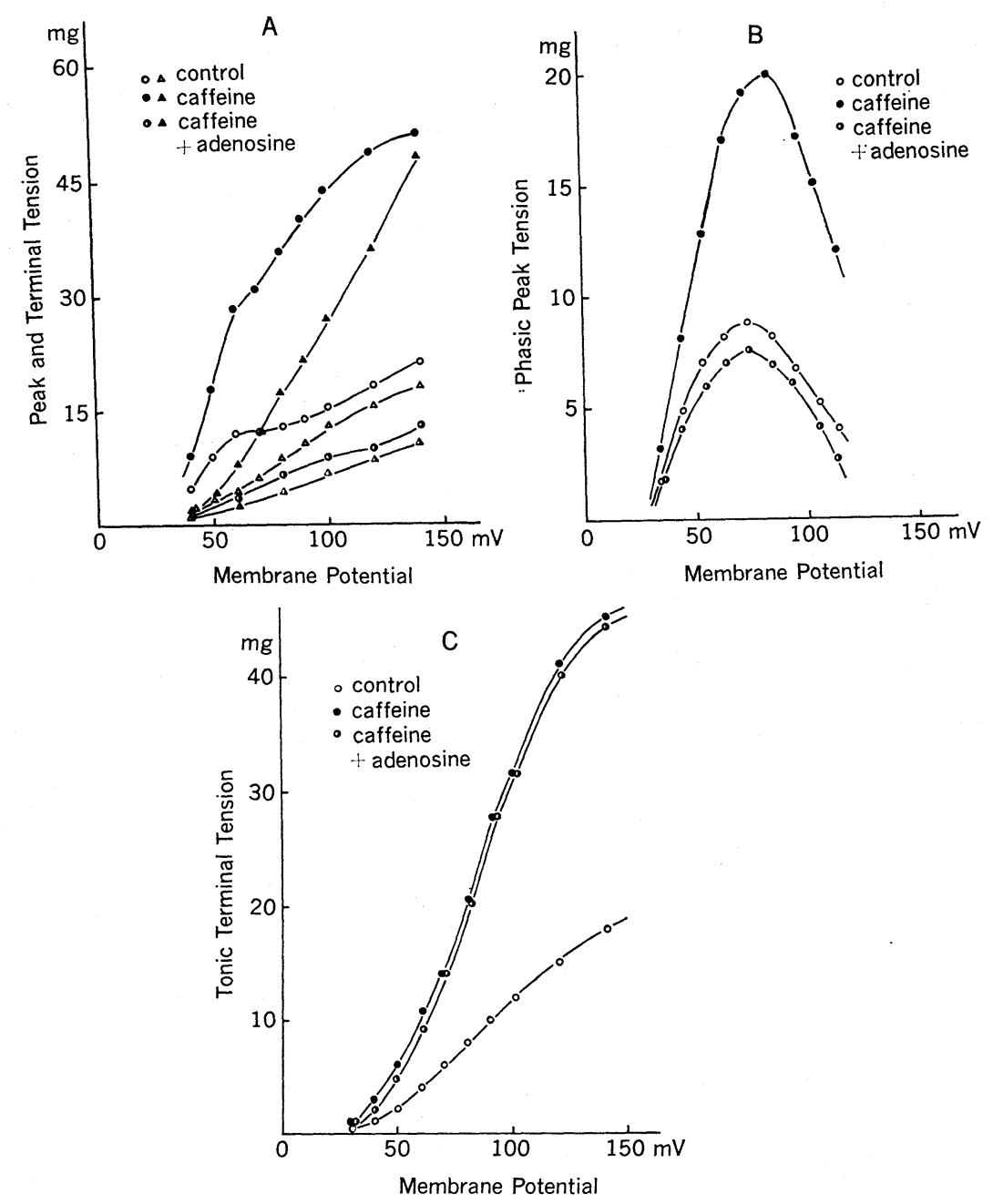

Fig. 8. Effects of caffeine and adenosine on tension components under voltage clamp. A) Voltage-tension relationships determined with long $2.0 \mathrm{sec}$ depolarizing pulses before $(\mathrm{O}, \triangle), 8-12 \mathrm{~min}$ after caffeine $(5 \mathrm{~mm}, \mathbf{0}, \mathbf{\Delta})$ and 8-12 min after replacement with adenosine ( $3 \mathrm{~mm}, \mathbf{\Delta}, \mathbf{\Delta})$. Circles show peak tension, and triangles, terminal tension levels. B) Relationships determined with short $50 \mathrm{msec}$ pulses which elicited $I_{\mathrm{Ca}}$-dependent tension. $\bigcirc$, before; $\bullet, 8-13 \mathrm{~min}$ after caffeine $(5 \mathrm{~mm})$; and $\odot, 11-15 \mathrm{~min}$ after further addition of adenosine $(3 \mathrm{~mm})$. C) $I_{\mathrm{Ca}}$-independent tension-voltage relationships obtained with long $2.0 \mathrm{sec}$ pulses under constant presence of $\mathrm{Mn}(3 \mathrm{mM})$. $\bigcirc$, before; ๑, 6-10 min after caffeine ( $5 \mathrm{~mm})$; and $\mathrm{c}, 5-10 \mathrm{~min}$ after further addition of adenosine ( $3 \mathrm{~mm})$. Figures show means of four series of experiments.

\section{Tension components and effects of drugs}

In the frog atrium, the contractile tension has been reported to consist of two 
components, a phasic $I_{\mathrm{Ca}}$-dependent tension and a tonic $I_{\mathrm{Ca}}$-independent tension (LÉOTY and RAYMOND, 1972; EINWÄCHTER et al., 1972). Figure 8 illustrates the effects of caffeine $(5 \mathrm{mM})$ and adenosine $(3 \mathrm{mM})$ on the voltage-tension relations determined with long and short pulses under voltage clamp. In $\mathrm{A}$, in which the peak (circles) and terminal tension (triangles) in response to $2.0 \mathrm{sec}$ depolarizing pulses were plotted against voltage, caffeine produced a marked augmentation of these tensions. When caffeine was replaced by adenosine, both the peak and terminal tensions were immediately suppressed to levels lower than those of the controls.

Figure $8 \mathrm{~B}$ shows the response of the $I_{\mathrm{Ca}}$-dependent phasic tension to short $(50 \mathrm{msec})$ depolarizing pulses in the constant presence of TTX. Again, caffeine $(5 \mathrm{mM})$ increased and further addition of adenosine $(3 \mathrm{mM})$ decreased the $I_{\mathrm{Ca}}$ dependent phasic tension. Figure $8 \mathrm{C}$ charts the data for the $I_{\mathrm{Ca}}$-independent tonic tension, which was examined with long $2.0 \mathrm{sec}$ pulses in the presence of $\mathrm{Mn}$. Significantly, the antagonistic action of caffeine and adenosine on the tension response disappeared in this solution. Caffeine $(5 \mathrm{~mm})$ still caused a marked augmentation of the tonic $I_{\mathrm{Ca}}$-independent tension, but further addition of adenosine $(3 \mathrm{mM})$ in this condition always failed to depress the augmented tension. Thus, it became clear that $\mathrm{Mn}$ ions eliminate the inhibitory effect of adenosine on the tonic tension component. The cause is not apparent at present.

\section{DISCUSSION}

The general conclusions of the present experiments are that caffeine exerts a specific stimulating effect on the excitation-contraction processes enhancing the slow inward current and the $I_{\mathrm{Ca}}$-dependent and independent tensions, and that adenosine is an effective and fairly specific antagonist to the actions of caffeine, depressing all of these current and tension components in normal Ringer solution. A competitive type of antagonism was also observed in the dose-tension response curves, and the threshold of negative inotropic effect of adenosine was substantially lowered in the presence of caffeine (Fig. 1 E). These observations qualitatively parallel those of DE GUBAREFF and SLEATOR (1965) of the action potential and tension in guinea-pig and human atria. The detailed effects of caffeine and adenosine are discussed in the following paragraphs (the names of the various currents are abbreviated for simplicity).

1. Effects of caffeine. The stimulating effect of caffeine on myocardium has long been known (HeathCote, 1920; Cheney, 1935). NAYLER (1963) showed that caffeine increases both inward and outward movement of $\mathrm{Ca}$ ions in isolated toad ventricle, and GUTHRIE and NAYLER (1967) obtained similar results in guinea-pig atria as noted. With a voltage clamp method, Кімото et al. (1974) determined that caffeine increased the slow inward current $\left(I_{\mathrm{s}}\right)$ and the delayed outward current $\left(I_{\mathrm{x}}\right)$. The present experiments, confirming these results, clarified 
the detailed kinetics. The stimulating effect of caffeine on $I_{\mathrm{s}}$ was principally due to increase of the limiting calcium conductance $\left(\bar{g}_{\mathrm{s}}\right)$ without altering the steady state activation and inactivation variables $\left(d_{\infty}, f_{\infty}\right)$. Thus, the peak voltage and time-course of $I_{\mathrm{s}}$ as well as the driving force were not appreciably affected. Quite comparable effects of theophylline on mammalian papillary muscles were recently reported by ScHOLZ and REuTER (1976). Theophylline increased $I_{\mathrm{Ca}}$ as well as $I_{\text {out }}$. The effect of theophylline on $I_{\mathrm{Ca}}$ was also due to an increase of $\bar{g}_{\mathrm{Ca}}$. There was no shift of $d_{\infty}$ along the voltage axis at $1 \mathrm{~mm}$, but a shift to more negative potentials occurred at $5 \mathrm{~mm}$. We also recognized a similar shift in frog atrium when caffeine in excess of $10 \mathrm{~mm}$ was used, especially at temperatures above $20^{\circ} \mathrm{C}$.

The increase of $I_{\mathrm{Ca}}$ may cause augmentation of $I_{\mathrm{Ca}}$-dependent tension, and caffeine also enhanced $I_{\mathrm{Ca}}$-independent tension. KAVALER et al. (1978), by adding caffeine during long-sustained depolarization in frog ventricle, demonstrated that the inotropic action of caffeine is entirely dependent on extracellular calcium. These observations support the hypothesis that increased permeability of ionized calcium and a consequent increase of $[\mathrm{Ca}]_{\mathrm{i}}$ underlie the positive inotropic action of caffeine. In this case, the increased $[\mathrm{Ca}]_{\mathrm{i}}$ would enhance the $I_{\mathrm{k} 1}$ directly and the $I_{\mathrm{x}}$ indirectly as observed in cardiac Purkinje fibers (IsENBERG, 1975, 1977). Enhancement of these currents was actually observed in later phases after addition of caffeine or in the higher concentrations. However, direct augmentation of $I_{\mathrm{x}}$ by caffeine cannot be neglected.

The initial slight inhibition of the background inward current $\left(I_{\mathrm{b}}\right)$ and the delayed outward current $\left(I_{\mathrm{x}}\right)$ upon adding caffeine, however, remained unexplained at present. Caffeine might be considered to exert an initial effect as a compound of purine-ribose moiety which is known to depress these currents (Gото et al., 1977).

2. Effects of adenosine, and antagonism between adenosine and caffeine. Goто et al. (1978) reported that adenosine inhibits the $I_{\mathrm{Ca}}$-dependent and independent tensions in the frog atrium, and that it also depresses the membrane currents, $I_{\mathrm{Na}}, I_{\mathrm{s}},\left(I_{\mathrm{Ca}}\right), I_{\mathrm{x}}$ and background current $\left(I_{\mathrm{b}}\right)$. Reconfirming these results, the present study further demonstrated that the depressant effects on the currents and the tension components were more conspicuous in the presence of caffeine. Kinetic analysis showed that adenosine depression of the $I_{\mathrm{s}}$, which had been priorly augmented by caffeine, was produced by inhibition of the $\bar{g}_{\mathrm{s}}$ without appreciable alteration of the activation and inactivation parameters, $d_{\infty}$ and $f_{\infty}$.

Since the report by DE GUbAREFF and SLEATOR (1965), it has been accepted that caffeine antagonizes the depressant effect of adenosine on mammalian myocardium. Similar antagonistic effects were reported between adenosine and catecholamine in perfused guinea-pig heart (SCHRADER et al., 1977) and in isolated bullfrog atrium (Gото et al., 1978). In the latter case, however, the antagonism appeared to be noncompetitive rather than competitive in the dose- 
tension response curves. Under voltage clamp conditions, adrenaline augmented $I_{\mathrm{Ca}}$ and $I_{\mathrm{Ca}}$-dependent tension but inhibited $I_{\mathrm{Ca}}$-independent tension, while adenosine depressed both the $I_{\mathrm{Ca}}$-dependent and independent tensions. Moreover, prior presence of adrenaline modified the effects of adenosine. With adrenaline, adenosine acted more selectively on $I_{\mathrm{Ca}}$ than on $I_{\mathrm{x}}$ and $I_{\mathrm{b}}$ (Goто et al., 1978).

The $\beta$-action of catecholamine is known to increase $I_{\mathrm{Ca}}, I_{\mathrm{Ca}}$-dependent tension and $I_{\mathrm{x}}$, and generally believed to act via cyclic $3^{\prime}, 5^{\prime}$-AMP (VASSORT et al., 1969; TSIEN et al., 1972; TsIEN, 1973, 1974; REUTER, 1974; TSIEN and WeINGART, 1976). These observations couple with the present results on the effect of caffeine and with the prior demonstration that caffeine and theophylline are inhibitors of phosphodiesterase, the enzyme responsible for the breakdown of cyclic AMP (SUTHERLAND and RAll, 1958; ButCHER and Sutherland, 1962). Actually, it was shown that, in guinea-pig heart, adenosine inhibits the catecholamine induced initial rise of cyclic AMP as well as the rise of glucose 1-phosphate and glucose 6-phosphate (SCHRADER et al., 1977). No corresponding study of the cyclic AMP level has been reported in terms of the interaction between adenosine and caffeine. However, under voltage clamp condition the antagonism between caffeine and adenosine on the phasic and tonic tensions as well as on the membrane current levels appeared to be more typical than the antagonism between adrenaline and adenosine.

On the other hand, there are some controversial observations that adenosine stimulates cyclic AMP accumulation in the guinea-pig ventricular slice preparation (HuANG and DRUMmOND, 1976) and causes an increase in the rate of cyclic AMP release from the dog ventricle (HuYNH-THU and LAMMERANT, 1978). These effects, however, have never been examined in the presence of epinephrine or caffeine. The sole action of adenosine causing a decrease of $[\mathrm{Ca}]_{\mathrm{i}}$ might result in a secondary increase of cyclic AMP, since in myocardium low concentrations of Ca stimulate adenylate cyclase (TADA et al., 1975) and inhibit cyclic AMP phosphodiesterase TEO and WANG, 1973).

Regarding the negative inotropic effect of adenosine, however, the secondary increase of cyclic AMP, if it exists, can hardly be considered to be the cause, especially when adrenaline or caffeine is present. Our observations that adenosine caused a marked inhibition of all of the membrane currents and tension components and that the effects were typical in the $I_{\mathrm{s}}$, in which only $\bar{g}_{\mathrm{s}}$ was selectively suppressed, rather suggest a decrease of cyclic AMP.

The authors are grateful to Professor A. Simpson of Showa University for critical reading of the manuscript. This work was supported by a grant (348092) from the Ministry of Education, Science and Culture of Japan.

\section{REFERENCES}

Butcher, R. W. and Sutherland, E. W. (1962) Adenosine 3',5'-phosphate in biological materials: I. Purification and properties of cyclic $3^{\prime}, 5^{\prime}$-nucleotide phosphodiesterase and use of 
this enzyme to characterize adenosine $3^{\prime}, 5^{\prime}$-phosphate in human urine. J. Biol. Chem., 237: 1244-1250.

Cheney, R. H. (1935) Cardiac automaticity effects of caffeine and nicotine. I. Caffeine influence upon the response of the sino-auricular strip. III. Caffeine-nicotine antagonism in sino-auricular strip response. J. Pharmacol. Exp. Ther., 54: 213-221 and 230-235.

Drury, A. N. and Szent-GyörgYI, A. (1929) The physiological activity of adenine compounds with especial reference to their action upon the mammalian heart. J. Physiol. (Lond.), 68: 213-237.

EINWÄCHTER, H. M., HAAS, H. G., and KERN, R. (1972) Membrane current and contraction in frog atrial fibres. J. Physiol. (Lond.), 277: 141-171.

Goto, M., YATANI, A., and TsudA, Y. (1977) An analysis of the action of ATP and related compounds on membrane current and tension components in bullfrog atrial muscle. Jpn. J. Physiol., 27: 81-94.

Goto, M., Yatani, A., and Tsuda, Y. (1978) Stabilizing effects of adenosine on the membrane currents and tension components of the bullfrog atrium. Jpn. J. Physiol., 28: 611-625.

Grossman, A. and FurchGotT, R. F. (1964) The effects of various drugs on calcium exchange in the isolated guinea-pig left auricle. J. Pharmacol., 145: 162-172.

DE GubarefF, T. and Sleator, W. (1965) Effects of caffeine on mammalian atrial muscle and its interaction with adenosine and calcium. J. Pharmacol. Exp. Ther., 148: 202-214.

Guthrie, J. R. and NAYLER, W. G. (1967) Interaction between caffeine and adenosine on calcium exchangeability in mammalian atria. Arch. Int. Pharmacodyn. Ther., 170: 249-255.

Heathcote, R. S. A. (1920) The action of caffeine, theobromine and theophylline on the mammalian and batrachian heart. J. Pharmacol. Exp. Ther., 16: 327-343.

Hollander, P. B. and WebB, J. L. (1957) Effects of adenine nucleotides on the contractility and membrane potentials of rat atrium. Circ. Res., 5: 349-353.

Horackova, M. and VASSORT, G. (1976) Calcium conductance in relation to contractility in frog myocardium. J. Physiol. (Lond.), 259: 597-616.

Huang, M. and Drummond, G. I. (1976) Effects of adenosine on cyclic AMP accumulation in ventricular myocardium. Biochem. Pharmacol., 25: 2713-2719.

Huynh-Thu, T. and LAmmerant, J. (1978) Adenosine-induced release of cyclic adenosine $3^{\prime}, 5^{\prime}$-monophosphate from the left ventricle in the anaesthetized intact dog. J. Physiol. (Lond.), 27: 641-654.

ISENBERG, G. (1975) Is potassium conductance of cardiac Purkinje fibres controlled by $\left[\mathrm{Ca}^{2+}\right]_{\mathrm{i}}$ ? Nature, 253: 273-274.

IsenBerg, G. (1977) Cardiac Purkinje fibres. [Ca $]_{i}$ controls the potassium permeability via the conductance components $g_{\mathrm{k} 1}$ and $g_{\mathrm{k} 22}$. Pflügers Arch., 371: 77-85.

Johnson, E. A. and McKinnon, M. G. (1956) Effects of acetylcholine and adenosine on cardiac cellular potentials. Nature, 178: 1174-1175.

Kavaler, F., ANderson, T. W., and Fisher, V. I. (1978) Sarcolemmal site of caffeine's inotropic action on ventricular muscle of frog. Circ. Res., 42: 285-290.

Кiмото, Y., SAiтo, M., and Goto, M. (1974) Effects of caffeine on the membrane potentials, membrane currents and contractility of the bullfrog atrium. Jpn. J. Physiol., 24: 531-542.

LÉOTY. CL. and RAYMOND, G. (1972) Mechanical activity and ionic currents in frog atrial trabeculae. Pflügers Arch., 334: 114-128.

Meinertz, T., Nawrath, H., and Scholz, H. (1973) Influences of cyclization and acyl substitution on the inotropic effects of adenine nucleotides. Naunyn-Schmiedeberg's Arch. Pharmacol., 278: 165-178.

NAYLER, W. G. (1963) Effect of caffeine on cardiac contractile activity and radiocalcium movement. Am. J. Physiol., 204: 969-974.

ReuteR, H. (1974) Localization of beta adrenargic receptors, and effects of noradrenaline 
and cyclic nucleotides on action potentials, ionic currents and tension in mammalian cardiac muscle. J. Physiol. (Lond.), 242: 429-451.

Scholz, H. and ReUTER, H. (1976) Effects of theophylline on membrane currents in mammalian cardiac muscle. Naunyn-Schmiedeberg's Arch. Pharmacol., 293: R19.

Schrader, J., BaumanN, G., and Gerlach, E. (1977) Adenosine as inhibitor of myocardial effects of catecholamines. Pflügers Arch., 372: 29-35.

Schrader, J., Rubio, R., and Berne, R. M. (1975) Inhibition of slow action potentials of guinea pig atrial muscle by adenosine: A possible effects on $\mathrm{Ca}^{++}$influx. J. Mol. Cell. Cardiol., 7: 427-433.

Sutherland, E. W. and RALl, T. W. (1958) Fractionation and characterization of a cyclic adenine ribonucleotide formed by tissue particles. J. Biol. Chem., 232: 1077-1091.

TADA, M., Kirchberger, M. A., Iorio, J.-A. M., and Katz, A. M. (1975) Control of cardiac sarcolemmal adenylate cyclase and sodium, potassium-activated adenosinetriphosphatase activities. Circ. Res., 36: 8-17.

Teo, T. S. and WANG, J. H. (1973) Mechanism of activation of a cyclic adenosine $3^{\prime}: 5^{\prime}$-monophosphate phosphodiesterase from bovine heart by calcium ions. Identification of the protein activator as a $\mathrm{Ca}^{2+}$ binding protein. J. Biol. Chem., 248: 5950-5955.

Trautwein, W., McDonald, T.F., and Tripathi, O. (1975) Calcium conductance and tension in mammalian ventricular muscle. Pflügers Arch., 354: 55-74.

TsIEN, R. W. (1973) Adrenaline-like effects of intracellular iontophoresis of cyclic AMP in cardiac Purkinje fibres. Nature, 245: 120-122.

TsIEN, R. W. (1974) Mode of action of chronotropic agents in cardiac Purkinje fibers. J. Gen. Physiol., 64: 320-342.

Tsien, R. W., Giles, W., and Greengard, P. (1972) Cyclic AMP mediates the effects of adrenaline on cardiac Purkinje fibres. Nature, 240: 181-183.

Tsien, R. W. and WeIngart, R. (1976) Inotropic effect of cyclic AMP in calf ventricular muscle studied by a cut end method. J. Physiol. (Lond.), 260: 117-141.

TsudA, Y. (1979) The nature of the initial positive inotropic effect of K-depletion in bullfrog atrial muscle. Jpn. J. Physiol., 29: 103-117.

Vassort, G., Rougier, O., Garnier, D., Sauviat, M. P., Coraboeuf, E., and Gragouïl, Y. M. (1969) Effects of adrenaline on membrane inward currents during the cardiac action potential. Pfügers Arch., 309: 70-81.

YAtANi, A., Goto, M., and TsudA, Y. (1978) Nature of catecholamine-like actions of ATP and other energy rich nucleotides on the bullfrog atrial muscle. Jpn. J. Physiol., 28: 47-61. 